\title{
Etnomatemática: possíveis convergências sobre a ideia de Jogos de Linguagem
}

\section{Ethnomatematics: possible convergences on the idea of Language Games}

\author{
Janaína Mendes Pereira da Silva \\ janaina.mendes.ps@gmail.com \\ Regina da Silva Pina Neves \\ reginapina@gmail.com
}

\begin{abstract}
Resumo
Neste artigo, apresentamos uma pesquisa bibliográfica que tem por objetivo analisar as possibilidades de convergências entre a matemática, a etnomatemática e o pensamento filosófico de Ludwig Wittgenstein em sua obra "Investigações Filosóficas". Buscou-se repensar as concepções que temos da matemática, da etnomatemática e da prática pedagógica perpassando diferentes abordagens sobre a ciência matemática, seus fundamentos epistemológicos e seu ensino nas instituições acadêmicas. Apoiando-se nos pensamentos do filósofo Ludwig Wittgenstein e com base numa perspectiva etnomatemática em diferentes concepções, contextualizando os jogos de linguagem matemáticos.
\end{abstract}

Palavras-chave: Etnomatemática; Ludwig Wittgenstein; Jogos de Linguagem.

\begin{abstract}
In this article, we present a literature that aims to analyze the possibilities of convergence between mathematics, Ethnomathematics and philosophical thought of Ludwig Wittgenstein in his "Philosophical Investigations". He attempted to rethink the conceptions we have of mathematics, Ethnomathematics and pedagogical practice traversing different approaches to mathematical science, their epistemological foundations and its teaching in academic institutions. Relying on philosopher Ludwig Wittgenstein thoughts and based on a Ethnomathematics perspective on different conceptions, contextualizing the mathematical language games.
\end{abstract}

Keywords: Ethnomatematics; Ludwig Wittgenstein; Language Games.

\section{Introdução}

A matemática desempenha um papel fundamental nas ciências acadêmicas e nos processos de construção do conhecimento científico. Historicamente, a matemática, como disciplina acadêmica, desenvolveu-se e multiplicou-se em outras disciplinas, configurando-se como símbolo da Lógica e da Razão, assim tendo lugar especial dentro da civilização ocidental. A expansão do Ocidente a partir do Renascimento representou também a expansão da matemática como modelo de saber científico e pretensamente universal ${ }^{1}$.

\footnotetext{
${ }^{1}$ Lembrando que entre os filósofos pré-socráticos do mundo grego antigo, que agregava saberes e cosmologias de povos diversos da região mediterrânea, a escola pitagórica já via o número como regente da forma, como uma chave para acessar uma racionalidade universal: "Os assim chamados pitagóricos, tendo se dedicado às matemáticas, foram os primeiros a fazê-las progredir. Dominando-as, chegaram à convicção de que o princípio das matemáticas é o princípio de todas as coisas" (Arist., Metaph. I, 5, 985b apud BORNHEIM, 1997, p. 50).
} 
Assim, embora sejam hoje reconhecidas outras abordagens da matemática fora desse modelo dominante - inclusive de outras civilizações que tiveram influência na própria evolução dessa forma de conhecimento, como a hindu (com o sistema de numeração decimal e o zero, posteriormente divulgado pelos árabes, o que culminou na adoção do sistema de números indo-arábicos pelo Ocidente cristão na Idade Média), Lima (2008) - foi este modelo que prevaleceu quando se trata do desenvolvimento desta como disciplina acadêmica que se impôs globalmente.

No Brasil, segundo Carvalho (2004, p. 40), todas as universidades brasileiras, praticamente sem exceção, foram estabelecidas com base no formato das universidades europeias modernas e o conteúdo das disciplinas, em todos os cursos, se baseia exclusivamente no saber das ciências e das artes ocidentais. Configurou-se, assim, no meio acadêmico brasileiro, uma profunda exclusão dos diversos fundamentos de vida e de sabedoria dos povos indígenas, das agrupações populares, das comunidades negras, quilombolas e demais povos e comunidades tradicionais.

Nas últimas décadas, o formato excludente e eurocêntrico das ciências acadêmicas vem passando por questionamentos epistemológicos sobre o saber matemático e seus fundamentos. Esses questionamentos implicam em uma reflexão sobre os conceitos e que temos acerca do ser humano, da sociedade, da cultura e da educação. No caso do conhecimento matemático, esses esforços de reflexão deram origem a uma nova área de estudos que passou a ser conhecida como a Etnomatemática.

Também em termos pedagógicos esses questionamentos terminaram por ampliar o campo do conhecimento matemático, fomentando novos estudos que agregam propostas cada vez mais adequadas nas relações contemporâneas de ensino e aprendizado matemático. Estes estudos consistem em identificar as contribuições que um trabalho acadêmico pode trazer no sentido de abordar aspectos não abordados por outros trabalhos científicos, quando se tem em foco o campo de pesquisa de Educação Matemática ${ }^{2}$. Fantinato e Santos $(2012$, p.1) arriscam uma hipótese de que há poucos estudos relacionados especificamente sobre Etnomatemática. Assim, buscou-se, neste trabalho de conclusão de graduação em Licenciatura Plena em

Curiosamente, especula-se que Pitágoras desenvolveu seu teorema - que demonstra que as formas e as razões matemáticas são governadas por princípios decifráveis - em contato com os hindus.

2 A Educação Matemática é um campo do conhecimento que se dedica a estudar questões relativas ao ensino/aprendizagem de matemática. É um campo interdisciplinar que faz uso de teorias de outros campos teóricos, como a sociologia, a psicologia, a filosofia, para a construção de seu conhecimento, além de construir suas próprias teorias, Passos (2008). A Educação Matemática não se restringe a apenas estudar meios de fazer alunos alcançarem um conhecimento previamente estabelecido, mas também problematiza e reflete sobre o próprio conhecimento matemático. 
Matemática, investigar, em algumas abordagens científicas desta área de pesquisas e estudos, suas contribuições acerca do tema escolhido.

Assim, nesse artigo, iremos apresentar a trajetória da etnomatemática. Em seguida, analisaremos o pensamento de Ludwig Wittgenstein, em sua obra Investigações Filosóficas, para então buscarmos um diálogo entre a ideia de jogos de linguagem, formulada por Wittgenstein, e as discussões ocorridas no seio da etnomatemática.

Iniciar um processo de investigação exige reflexão e planejamento. Segundo Passos (2008), é necessário utilizar a reflexão no que se pretende investigar - realizando um processo de problematização da pesquisa - e utilizar o planejamento do modo de como se dará a procura por respostas ao problema de pesquisa. Deste modo, a partir desse processo, foram buscadas neste trabalho referências para refletir e planejar em duas fontes distintas: na literatura que aborda as perspectivas da Etnomatemática e nas reflexões acerca das ideias de Wittgenstein.

Para isso buscou-se apontar conexões entre elas, tendo em vista aspectos teóricos e práticos. Os objetivos dessa investigação apresentam-se também sob essa perspectiva teóricoprática, em estudar as possíveis conexões entre Etnomatemática com os estudos sobre as ideias de jogos de linguagem formuladas por Ludwig Wittgenstein em sua obra Investigações Filosófica, identificação na literatura o que caracteriza a Etnomatemática e a problematização da linguagem matemática transmitida e ensinada, a utilização como uma possibilidade de sustentação filosófica o pensamento de jogos de linguagem de Wittgenstein para reconhecer as possíveis conexões da Etnomatemática com os estudos de Wittgenstein.

O método de pesquisa adotado foi a pesquisa bibliográfica, na perspectiva da Etnomatemática. A metodologia caracterizada por uma pesquisa bibliográfica, segundo Marconi e Lakatos (2009), coloca o pesquisador em contato direto com tudo que já foi escrito sobre determinado assunto, permitindo ao pesquisador compreender a análise de sua pesquisa ou manipulação de suas informações.

Para a realização de um estudo teórico-filosófico da Etnomatemática e as ideias formuladas por Ludwig Wittgenstein em sua obra Investigações Filosóficas, em um primeiro passo, foi adotada a leitura e análise de algumas produções acadêmicas e literatura, tais como: dissertações e teses; anais de congressos; artigos em periódicos e livros. No segundo passo, após a seleção das produções acadêmicas e literatura. Fiorentini e Lorenzato (2006) a respeito de pesquisas bibliográfica ou de revisão, nos diz que, as modalidades que realizam análises, tendo como matéria documentos escritos e/ou produções culturais, compreendendo estudo analítico-descritivo, que permitam produzir novos resultados, daqueles já obtidos. No caso 
deste artigo realizando uma análise, extraindo as informações adicionais, que transcendam os limites das experiências já pesquisadas.

\section{A Etnomatemática}

Segundo Gerdes (1989), a Etnomatemática visa estudar as ideias matemáticas nas suas relações com o conjunto da vida cultural e social. Para D'Ambrosio (1998, p. 5-7), a Etnomatemática apresenta-se como veículo para se compreender, em diversos contextos culturais, o saber/fazer matemático ao longo da história da humanidade. Partindo da sua etimologia, explica-se o termo Etnomatemática fragmentando-o e analisando suas seguintes partes: etno, o ambiente natural, social, cultural e imaginário de determinado grupo humano; matema, a qual abrange as ações de explicar, aprender, conhecer; e tica, a qual se refere aos mecanismos, modos, às artes e técnicas empregadas nas ações de sobrevivência e de convívio social de determinado grupo humano.

D'Ambrosio (1999) defende que a matemática é uma manifestação cultural e, como tal, ela se manifesta diferentemente de acordo com os seus diversos contextos sociais e culturais. Conforme o mesmo autor, a Etnomatemática tem por objetivo compreender essas diferenças, podendo ser definida como um programa de pesquisa em história e filosofia da matemática, com implicações para o ensino da matemática e para a educação em geral. Essa dimensão pedagógica dos estudos em etnomatemática leva Wanderer (2013, p. 259) a relacionar essa linha de pesquisa ao pensamento de Paulo Freire, bem como à Psicologia Cognitiva, à Filosofia e à Antropologia.

\section{A Etnomatemática como Modelo Pedagógico}

A história da matemática perpassa várias civilizações, podendo, portanto, ser utilizada como instrumento de resgate da própria identidade cultural, conforme preconizam os Parâmetros Curriculares Nacionais (PCN's) de 1998:

[...] ao verificar o alto nível de abstração matemática de algumas culturas antigas, o aluno poderá compreender que o avanço tecnológico de hoje não seria possível sem a herança cultural de gerações passadas. Desse modo, será possível entender as razões que levam alguns povos a respeitar e conviver com práticas antigas de calcular, como o uso do ábaco, ao lado dos computadores de última geração. (BRASIL, 1998, p.43).

Os Parâmetros Curriculares Nacionais também orientam que o ensino da história da matemática seja utilizado para relacionar os conceitos matemáticos ao contexto cultural em que foram desenvolvidos, aos problemas e situações históricas que demandavam soluções. 
A própria história da matemática mostra que ela foi construída como resposta a perguntas provenientes de diferentes origens e contextos, motivadas por problemas de ordem prática (divisão de terras, cálculo de créditos), por problemas vinculados a outras ciências (Física, Astronomia), bem como por problemas relacionados a investigações internas à própria matemática. (BRASIL, 1998, p. 40).

O ensino da matemática deveria, portanto, mostrar essa presença da matemática em todas as dimensões da vida. No entanto, constata D'Ambrosio (1999), um dos maiores erros das práticas educativas é desvincular a prática em educação de outras atividades humanas, e isso acontece em particular com o ensino da matemática. Na perspectiva de D’Ambrosio, é impossível discutir práticas educativas sem recorrer à história, cultura e tradições que moldam diferentes estilos de aprendizagem. D’Ambrosio utiliza, então, a linha de pensamento de Paulo Freire para repensar a educação matemática, caminho que, conforme indica o autor, já havia sido trilhado pela educadora matemática Marilyn Frankenstein.

Sendo a matemática uma construção social, Santos (2006, s/p) se pergunta sobre o papel da etnomatemática no ensino de matemática: se ela serve como elemento motivador para a aprendizagem da matemática tradicional, ou se ela aponta para a substituição dos conteúdos da matemática formal pelos conteúdos da matemática de cada grupo social em particular? Ao tentar responder a essa pergunta, Santos ressalta a importância da contextualização e do diálogo não apenas para apresentar conceitos matemáticos, mas também como fundamento da relação pedagógica:

[...] a etnomatemática não como um método de ensino em si, mas sim como detentora de relações inclusivas entre professores e alunos e das diversas formas de conhecer presentes em contextos culturais/socioculturais diferentes. [...] Dessa forma, entendemos o 'diálogo', a 'contextualização' e a 'comparação', como pilares que alicerçam a pedagogia etnomatemática podendo, ainda, ser entendidos como posturas necessárias ao professor dentro dessa pedagogia. (SANTOS, 2006, s/p)

Entendendo a etnomatemática como ação pedagógica, Knijnik (2001) propõe uma abordagem etnomatemática através da investigação das concepções, tradições e práticas matemáticas de um determinado grupo social. Nesta perspectiva, a etnomatemática deve evoluir naturalmente de uma perspectiva antropológico-etnográfica para assumir uma dimensão voltada para a ação pedagógica, manifestando a intenção de incorporar a etnomatemática ao currículo acadêmico.

Para além de estimular a criatividade, Bicudo e Miarka (2012, p. 158) propõem que a etnomatemática seja um instrumento de análise crítica e reflexiva, e que "[...] abram aos horizontes do pensar a matemática e [suas] interligações com a linguagem e modos de compreender a sociedade, a história e a vida. 
A etnomatemática defende, portanto, uma perspectiva pluralista de se entender a matemática, como bem esclarece Clareto (2002, p.34): "Abordagens etnomatemáticas têm dado ênfase a se pensar a matemática no plural, as matemáticas, como produtos culturais de diferentes grupos".

Há diferentes concepções de matemática no campo de pesquisa em Etnomatemática, que, conforme Bicudo e Miarka (2012, p. 156), leva os pesquisadores a desenvolverem diferentes metodologias, com potenciais próprios e formas distintas de conceber a relação entre matemática e Etnomatemática:

\begin{abstract}
Ela pode ser encontrada na etnomatemática, no sentido de que a "Matemática Ocidental" é interna à etnomatemática, tomada esta, por sua vez, como um campo mais amplo, o que pode ser percebido na pesquisa de D'Ambrosio e de Barton. Para Knijnik, a etnomatemática é uma alternativa para a matemática (ou), ao tomar as práticas dos grupos culturais como jogos de linguagem que podem ser relacionados por meio de semelhanças de família, sem um núcleo uno como base para essa constituição. Para um terceiro grupo, formado por Gerdes e Sebastiani Ferreira, a matemática é algo abraçado à etnomatemática (e), ao conceber a matemática como um núcleo sólido direcionador da prática do pesquisador desse campo. (BICUDO; MIARKA, 2012, p. 156-157).
\end{abstract}

Bicudo e Miarka (2012) acrescentam que, por meio da Filosofia da Linguagem de Wittgenstein, a pesquisadora Gelsa Knijnik encontrou subsídios para discutir a relação entre matemática e linguagem tendo como referência os jogos de linguagem de Wittgenstein e assim assumindo a existência de diferentes matemáticas no conjunto de jogos de linguagem.

\title{
Wittgenstein - Jogos de Linguagem
}

No livro Investigações Filosóficas, Ludwin Wittgenstein elabora uma crítica à filosofia tradicional, apresentando a linguagem como uma atividade humana e não como contendo uma essência. Na obra publicada postumamente em 1953, o pensamento de Wittgenstein muda completamente em relação ao que ele havia escrito em seu primeiro livro - Tractatus Logicophilosophicus. Para Cassavane (2009), o pensamento do filósofo é caracterizado, em sua segunda fase ${ }^{3}$, por uma forte crítica à tradição filosófica, propondo que o pensamento tem por objetivo não a verdade ou respostas às questões filosóficas ${ }^{4}$ mas apenas "fazer pensar". Em sua obra publicada postumamente, Wittgenstein (1999), afirma que: "não desejaria, com

\footnotetext{
${ }^{3}$ As expressões "segunda fase", "fase madura", "obra de maturidade" e "segundo Wittgenstein" tornaram-se correntes para designar a filosofia de maturidade do filósofo austríaco, com a obra Investigações Filosóficas. Assim, essas expressões serão utilizadas neste artigo.

${ }^{4}$ Hacker (2000) nos ajuda a compreender o pensamento de Wittgenstein e esclarece que segundo o filósofo "Os problemas filosóficos surgem, antes de mais nada, de particularidades desencaminhadoras da linguagem, pois nossa linguagem apresenta conceitos muito diferentes sob uma aparência semelhante" (HACKER, 2000, p. 12). Ainda de acordo com Hacker (2000), segue-se a essa crítica de Wittgenstein a ideia de que "A tarefa da filosofia é resolver ou dissolver os problemas filosóficos por meio de um esclarecimento do sentido (HACKER, 2000, p. 12).
} 
minha obra, poupar aos outros o trabalho de pensar, mas sim, se for possível, estimular alguém a pensar por si próprio".

Vale levar em consideração que o livro se trata de um texto polifônico, a saber, constituído por várias vozes, que são os interlocutores "fictícios" de Wittgenstein. Isto ocorre na citação $§ 65$ desta obra, em que aparece a voz de um interlocutor essencialista exige de Wittgenstein o que deve haver de comum a todas as linguagens, para que possam ser chamadas de linguagem. Neste trecho, como em outros diversos, não se trata de uma posição do próprio Wittgenstein, mas pelo contrário, esta perspectiva filosófica essencialista será objeto de terapia filosófica, ao longo dos próximos parágrafos seguidos da obra. No entanto, para Wittgenstein, os conceitos em geral são intrinsecamente vagos, as definições precisas são a posteriori, para finalidades específicas.

Segundo Neves (2014), quando se atenta para a leitura das Investigações Filosóficas, percebe-se que é por meio das regras da gramática, e não por regras de representação, que a linguagem funciona. Neves destaca a importância da distinção wittgensteiniana entre o uso da linguagem como representação e o seu uso como um instrumento que leva à ação. A compreensão da linguagem como algo social faz com que a busca por uma fórmula que explique o seu funcionamento torne-se irrelevante, pois um jogo de linguagem apenas deve ser jogado e não explicado. Não pode existir nenhuma justificativa a não ser dizer que jogamos um jogo de linguagem:

\footnotetext{
Assim, para o Wittgenstein II apanhar algo relevante sobre o significado não demandaria outra coisa senão conservarmos o que é entender uma linguagem. E entender uma linguagem nada seria senão a atividade de usar uma técnica, uma espécie de know how. Especificamente, entender uma linguagem demanda observar o uso para ver como é que é "seguir uma regra". E como só sabemos se estamos seguindo uma regra quando participamos do jogo, usar bem os jogos de linguagem é usá-los socialmente. A linguagem só é linguagem como prática social. (GIRALDELLI, 2012, p. 105 apud NEVES, 2014 p. 17).
}

Em Investigações Filosóficas (WITTGENSTEIN, 1999, p. 30), o conceito de jogos de linguagem abrange as atividades linguísticas, os processo de denominação de objetos e repetições das palavras, bem como o conjunto de linguagem e das atividades a elas interligadas. Wittgenstein considera o significado de uma palavra inseparável do seu uso na linguagem (WITTGENSTEIN, 1999, p.43, §43). Esta expressão analógica ressalta que as diferentes linguagens, assim como os jogos, são práticas reguladas por padrões públicos que definem como são ou serão admitidos.

Quando Wittgenstein estende a analogia do jogo à linguagem como um todo, e não só aos sistemas axiomáticos, seu objetivo não era formular uma linguagem ideal para substituir à 
existente. Sua finalidade é demonstrar uma visão panorâmica da funcionalidade da linguagem, explicitando o sentido e o significado das palavras em um contexto.

Quero chamar esses jogos de "jogos de linguagem", e falar de uma linguagem primitiva às vezes como de um jogo de linguagem. E poder-se-ia chamar também de jogos de linguagem os processos de denominação das pedras e de repetição da palavra pronunciada. Pense em certo uso que se faz das palavras em brincadeiras de roda. Chamarei de "jogo de linguagem" também a totalidade formada pela linguagem e pelas atividades com as quais ela vem entrelaçada. (WITTGENSTEIN $1999, \S 85)$

O termo “jogo de linguagem”, tem como principal função destacar as várias semelhanças entre linguagem e jogos, como algo equivalente a um cálculo. Neste caso, para o lugar em que os jogos de linguagem ocupam nas práticas humanas, ou seja, para uma visão dos efeitos práticos da linguagem. Para Ruy (2008, p. 1), segundo o filósofo, "o significado de uma palavra não é um objeto que a sucede, mas é determinado pelas regras que norteiam seu funcionamento". Aprendemos o significado das palavras aprendendo a usá-las, assim como os jogos, isto é, com o uso, com a prática, com a observação (WITTGENSTEIN, 1999, $\S \S 23,1999)$.

Do mesmo modo, o autor fala da noção de semelhanças de família onde representa um modelo do complexo funcionamento da linguagem, repetida ou renovada pelas maneiras que possam ser utilizadas. O que há de semelhanças entre os diversos tipos de jogos? Isso não pode ser descrito, como o mesmo diz, mas simplesmente "visto", algo que nos levará a contemplar semelhanças ou parentescos surgindo e desaparecendo, "e digo: os jogos formam uma família" (WITTGENSTEIN, 1999). Porém, é possível, encontrarmos uma rede complexa de parentescos, de semelhanças e diferenças surgindo e desaparecendo entre os vários tipos de jogos:

Considere, por exemplo, os processos que chamamos de "jogos". Refiro- me a jogos de tabuleiro, de cartas, de bola, torneios esportivos, etc. O que é comum a todos eles? Não diga: "Algo deve ser comum a eles, senão não se chamariam "jogos",, mas veja se algo é comum a eles todos. -Pois, se você os contempla, não verá na verdade algo que fosse comum a todos, mas verá semelhanças, parentescos, e até toda uma série deles. Como disse: não pense, mas veja! Considere, por exemplo, os jogos de tabuleiro, com seus múltiplos parentescos. Agora pense nos jogos de cartas: aqui você encontra muitas correspondências com aqueles da primeira classe, mas muitos traços comuns desaparecem e outros surgem. Se passarmos agora aos jogos de bola, muita coisa comum se conserva, mas muitas se perdem. São todos 'recreativos'? Compare o xadrez com um jogo de amarelinha. Ou há em todos um ganhar e um perder, ou uma concorrência entre os jogadores? Pense nas paciências. Nos jogos de bola há um ganhar e um perder; mas se uma criança atira a bola na parede e a apanha outra vez, este traço desapareceu. (...). Pense agora nos brinquedos de roda: o elemento divertimento está presente, mas quantos dos outros traços característicos desapareceram! E assim podemos percorrer muitos, muitos outros grupos de jogos e ver semelhanças surgirem e desaparecerem [...] (WITTGENSTEIN. 1999, p. 52, §66). 
Com relação a noção de semelhanças de família insistirá que não é possível uma definição precisa, pois se pensarmos em família, existe um cruzamento de semelhanças e diferenças que há entre os membros familiares. Este contexto auxiliará para apresentar as possíveis convergências das noções de jogos de linguagem com a proposta de Etnomatemática. Além do que, não se considera a questão de que a reflexão fillosófica não leva necessariamente e nem, muito menos, de modo imediato a implicações metodológicas.

[...] apontando semelhanças de práticas àquelas práticas consideradas matemáticas por matemáticos. Essas práticas similares constituiriam semelhanças de família, de acordo com o referencial wittgensteiniano. Esse grupo de práticas é chamado desse modo porque não solicita uma característica nuclear que articula as práticas. Ao invés disso, as práticas podem ser semelhantes em pares, como em uma família. Um filho pode ter seu nariz similar ao de seu pai, seus lábios similares aos de sua irmã, suas orelhas às de seu avô, sem, necessariamente, ocorrerem as mesmas semelhanças entre pai e filha, ou entre avô e neta. (BICUDO; MIARKA, 2012 p. 156).

Para Wittgenstein, por exemplo, a multiplicidade da linguagem envolve, sim, um uso referencial das palavras, ou seja, não é descartada a função da linguagem como representação dos fatos do mundo. Apenas ressalta que esta não é a sua única função, onde há muitos outros usos de nossas palavras e expressões linguísticas. Para Wittgenstein, por exemplo, a multiplicidade da linguagem envolve, sim, um uso referencial das palavras, ou seja, ele não descarta a função da linguagem como representação dos fatos do mundo, tampouco abandona a busca de fundamentos para elas, apenas mostra que estes são de natureza convencional, são as regras que seguimos para atribuir sentido aos fatos do mundo. Em outras palavras, estes fundamentos estão na própria linguagem

\section{As possíveis conexões entre Etnomatemática e a ideia de Jogos de Linguagem formuladas por Ludwig Wittgenstein}

Para Vilela (2007, p. 139), as noções de Wittgenstein de jogo de linguagem, regras e formas de vida podem esclarecer os conceitos para interpretar as matemáticas e seus conceitos como fazendo parte de jogos de linguagem sujeitos a regras específicas conforme a situação. Em sua pesquisa, Vilela apresenta os conceitos de jogo de linguagem, semelhança de família, regras e formas de vida de Wittgenstein, situando a filosofia de Wittgenstein dentro da história da filosofia e delineando a concepção referencial à qual Wittgenstein se opõe. Os jogos de linguagem, assim, poderiam ajudar a compreender a matemática como prática social:

\footnotetext{
Nesta discussão, consideramos as elaborações de Wittgenstein sobre a força da gramática profunda e nos inspiramos nas interpretações de Bloor (1998), que também parte de Wittgenstein para enfatizar o caráter social da matemática. Especificamente, consideramos o que Bloor denomina caráter coercitivo da matemática numa interpretação própria: ao reconhecer a matemática como um
} 
conjunto de regras que funcionam como critérios públicos de verdade, somos induzidos a não perceber diferenças entre práticas matemáticas diferentes. Ao contrário, ao perceber distinções entre práticas matemáticas tendemos, ou a excluí-la do que é chamado matemática, ou a desconsiderá-las para manter a sustentação da unicidade da matemática: 'não vemos o que fomos treinados a não ver'. (VILELA, 2007, p. 139-140).

Na visão de Machado (2006, p. 12), as reflexões da fase madura de Wittgenstein apresentam a história da filosofia, em grande parte, com uma sucessão de confusões gramaticais e de tentativas de lidar com essas confusões que surgem naturalmente devido à forma superficial da nossa linguagem. A solução deste problema, assim, "depende apenas de uma organização do nosso conhecimento do uso da linguagem".

Para Duarte e Magalhães (2013), as ideias de Wittgenstein questionam a ideia de uma linguagem matemática dita universal, já que para o pensador austríaco os significados das palavras dependerão de seus usos nos diversos contextos dos quais fazem parte. Não existindo fundamento último que não as relações e construções sociais, as matemáticas, nas diferentes culturas, seriam compreendidas como um conjunto de jogos de linguagem, usando das semelhanças de famílias para produzir os critérios de racionalidade, como destaca Condé (2004, p. 29):

A gramática e as interações dos jogos de linguagem constituem as teias da razão. Em outros termos, perante a crise da racionalidade, no lugar da razão abstrata, centralizada e fundacionista que caracterizou o pensamento moderno, Wittgenstein "propõe" a gramática e os jogos de linguagem como uma racionalidade que se forja a partir das práticas sociais em uma forma de vida e que não mais se assenta em fundamentos últimos. (CONDÉ, 2004 p. 29).

O pensamento tardio de Wittgenstein pode apresentar efetiva convergência com a proposta da Etnomatemática de dialogar com uma grande diversidade de saberes e racionalidades. Considerando que a linguagem matemática acadêmica é constituída por símbolos que se diz serem neutros e universais, Wanderer (2013, p. 265) aponta dois elementos caros à Etnomatemática que são baseados na obra de Wittgenstein: a evidência de distintas racionalidades e a problematização das regras que constituem os jogos de linguagem matemática acadêmica. Compartilhando tal linha de raciocínio, Knijnik e Wanderer questionam:

Se Wittgenstein, na segunda fase de sua trajetória intelectual, nega a existência de uma linguagem universal, tal posição leva a questionar a noção de uma linguagem matemática universal, o que aponta para a produtividade do pensamento do filósofo para atribuir novos sentidos para os fundamentos da etnomatemática. (KNIJNIK; WANDERER, 2008, p. 558). 
Para Duarte e Magalhães (2013, p. 2-3), a Etnomatemática, ao analisar com atenção os jogos de linguagem associados a outras racionalidades, que não a matemática escolar e acadêmica, possibilita a problematização do caráter universal do conhecimento matemático:

[...] esta 'grande narrativa' que é a matemática acadêmica - considerada pela modernidade como a linguagem por excelência para dizer o universo mais longínquo e também o mais próximo - introduzindo uma temática até então ausente no debate da Educação Matemática. (DUARTE; MAGALHÃES, 2014, p. 3, apud KNIJNIK et al., 2012, p. 24).

Knijnik e Wanderer (2008, p. 558), destacam que o pensamento da fase madura de Wittgenstein é produtivo quando se quer pensar em diferentes matemáticas, que ganham sentido em seus usos e o interesse do papel da linguagem na constituição do mundo, suscitando novas epistemologias que sustentem, filosoficamente, a matemática.

Assim, pode-se dizer que as matemáticas produzidas pelos diversos grupos culturais, em diferentes formas de vida configuram critérios de racionalidade específicos (WANDERER, 2013). De acordo com essa perspectiva, o significado atribuído à expressão "educação matemática" é convergente com as posições de Knijnik (2001, 2003, 2010) e Knijnik e Wanderer (2008), que a considera como processos, envolvendo o aprender e o ensinar matemática, que se desenvolvem em espaços educativos escolares e não escolares diversos. Wanderer (2012) apresenta:

Desta forma, a matemática acadêmica, a matemática escolar, as matemáticas camponesas, as matemáticas indígenas, em suma, as matemáticas geradas por grupos culturais específicos podem ser entendidas como conjuntos de jogos de linguagem associados a diferentes formas de vida, agregando critérios de racionalidade específicos. Porém, esses diferentes jogos não possuem uma essência invariável que os mantenha completamente incomunicáveis uns dos outros, nem uma propriedade comum a todos eles, mas algumas analogias ou parentescos... (WANDERER, 2012, p. 56).

A existência de uma realidade matemática extralinguística que desse sentido às suas proposições, contaria com objetos matemáticos, que existiriam ou pré-existiriam, seja no mental, no empírico ou na subjetividade social.

Pelo exposto até aqui, pode-se dizer que os argumentos da obra de maturidade de Wittgenstein permitem que se compreendam as matemáticas associadas a diferentes formas de vida como conjuntos de jogos de linguagem que possuem semelhanças entre si, convergindo com as reflexões ocorridas no campo da Etnomatemática. Sendo a linguagem uma forma de comunicação, e considerando que a determinação do significado de uma palavra depende de nossa interpretação e do nosso objetivo com o seu uso, a linguagem não pode ser determinada de modo definitivo, não se pode generalizar definindo uma entidade abstrata. $O$ estudo da matemática deve ser feito a partir de outros jogos de linguagem e criando pontes de conexão com os jogos da matemática acadêmica, trazendo a Etnomatemática para dentro da educação matemática. 


\section{Considerações Finais}

Buscamos nesse estudo primeiro, identificar o que caracteriza a Etnomatemátcia e sua problematização da linguagem transmitida e ensinada, assim apresentar como a ideia wittgensteiniana de jogos de linguagem pode contribuir para a concepção da matemática, da Etnomatemática e do ensino de matemática nas instituições acadêmicas.

Segundo utilizar como sustento o pensamento de jogos de linguagem da obra de maturidade de Wittgenstein, onde o conceito de semelhanças de família traz novas perspectivas sobre o que se considera cientifico, ou melhor, o que faz com que se estabeleça a distinção entre cientifico e não-científico, que são o conjunto das práticas, das regras e dos resultados científicos. Wittgenstein também elabora uma concepção de linguagem dentro das formas de vida, no qual tenta provar que a linguagem tem sempre uma origem e um uso comum, ou seja, a possibilidade do significado seria dependente de um uso comum das palavras que acontece dentro do o uso dos jogos de linguagem.

E terceiro reconhecer as conexões da Etnomatemática com os estudos Wittgenstein, em que Etnomatemática apresenta uma abordagem sociocultural e cognitiva, sendo um dos campos da educação matemática que vem despertando o interesse de educadores, estudiosos e pesquisadores que muitas vezes buscam soluções para os problemas relacionados ao seu ensino da matemática. Dentro deste campo de pesquisa são fornecidas algumas bases para se entender as relações entre linguagem e a construção ou apropriação de significados matemáticos, reconhecendo que todas as culturas e todos os povos desenvolvem maneiras de explicar, conhecer e lidar com suas realidades. As matemáticas, nas diferentes culturas, se conformam como conjunto de jogos de linguagem que possuem semelhanças entre si e que funcionam, nas relações sociais, como estruturas linguísticas, sujeitas à difusão, manutenção e transformação. Conforme expõe Wanderer (2013), as matemáticas geradas por diversos grupos culturais podem ser compreendidas como um conjunto de jogos de linguagem produzidos em diferentes formas de vida.

É preciso trazer para a sala de aula outros olhares, que envolvem diferentes concepções de matemática, de modo a dissolver imagens exclusivistas e privilegiadas de se pensar essa forma de conhecimento. A Etnomatemática vem assim desempenhando relevante papel para a educação matemática.

\section{Referências}

BRASIL. Parâmetros Curriculares Nacionais (PCNs): A reforma curricular e a organização do Ensino Médio, 1998. Brasília, DF. Disponível em < www. mec.gov.br>. Acesso em: 17 jul. 2015.

BICUDO, Maria Aparecida Viggiani; MIARKA, Roger. Matemática e/na/ou Etnomatemática? Revista Latinoamericana de Etnomatemática. San Juan de Pasto, Colômbia. v. 5, n.. 1, p. 149-158. 
2012. Disponível em: <http://dialnet.unirioja.es/servlet/articulo?codigo=3894645>. Acesso em: 10 mai. 2015.

BORNHEIM, Gerd (org.). Os filósofos pré-socráticos. São Paulo: Cultrix, 1997.

CARVALHO, José Jorge de. Uma Proposta de Cotas para Negros e Índios na Universidade de Brasília. O Público e o Privado. Fortaleza. no. 3, p. 09-59, jan.jun. 2004.

CAVASSANE, Ricardo Peraça. A natureza da crítica do segundo Wittgenstein à tradição filosófica. Revista de Iniciação Científica da Faculdade de Filosofia e Ciências. Marília: Ed: UNESP. v. 10, n. 2, 2009. Disponível em: <www.marilia.unesp.br/Home/.../RicardoPeraca(72-81).pdf>. Acessado em: 18 mai. 2015.

CLARETO, Sônia Maria. Educação Matemática e Contemporaneidade: enfrentando discursos pósmodernos. BOLEMA, Rio Claro, SP. Ano 15, n. 17, p. 20-39. 2002.

CONDÉ, Mauro Lúcio Leitão. As teias da Razão: Wittgenstein e a Crise da Racionalidade Moderna. Belo Horizonte: Argvmentm Editora, 2004.

D’AMBROSIO, Ubiratan. Etnomatemática: arte ou técnica de explicar e conhecer. 5. ed. São Paulo: Ática, 1998, p. 5-7.

D’AMBROSIO, Ubiratan. A história da matemática: questões historiográficas e políticas e reflexos na Educação Matemática. In: BICUDO, M. A. V.(org.). Pesquisa em Educação Matemática: concepções e perspectivas. São Paulo: UNESP, 1999. p. 97-115.

DUARTE, Claúdia Glavan; MAGALHÃES, Amanda. Jogos de linguagem matemáticos de mulheres rendeiras de Florianópolis-SC-Brasil. Memorias I CEMACYC. Santo Domingo, República Dominicana: CEMACYC, p. 1-10, 2013. Disponível em: < http://funes.uniandes.edu.co/4232/>. Acessado em: 18 mai. 2015.

FANTINATO, Maria Cecília; SANTOS, Fábio, Lennon Marchon dos. Possibilidades para "uma" Fundamentação Teórica da Etnomatemática? Boletim do LABEM. Niteroi. ano 3, n. 5, jul/dez de 2012. Disponível em: <www.labem.uff.br/images/Boletim...n.5/boletim_labem_pp.1-8.pdf $>$. Acesso em: 14 de mar. 2015.

FIORENTINI, Dário; LORENZATO, Sérgio. Investigação em educação matemática: percursos teóricos e metodológicos. Campinas: Autores Associados, 2006.

GERDES, Paulus. Sobre aritmética e ornamentação geométrica: análise de alguns cestos de índios do Brasil. BOLEMA, Special no.1, 11-34, reproduzido em: QUIPU, 1989, 6, 171-187, 1989.

HACKER, Peter Michael Stephan. Wittgenstein: sobre a natureza humana. São Paulo: Unesp, 2000.

KNIJNIK, Gelsa. Educação matemática, exclusão social e política do conhecimento. Bolema. Rio Claro, SP. vol. 16, p. 12-28, 2001.

KNIJNIK, Gelsa. Currículo, etnomatemática e educação popular: um estudo em um assentamento sem terra. Currículo Sem Fronteiras, on line, v. 3, n. 1, p. 96-110, 2003.

KNIJNIK, Gelsa. Itinerários da etnomatemática: questões e desafios sobre o cultural, o social e o político na educação matemática. In: KNIJNIK, Gelsa. et all (orgs). Etnomatemática: currículo e formação de professores. Santa Cruz do Sul: Edunisc, 2010. 
KNIJNIK, Gelsa; WANDERER, Fernanda. Discursos produzidos por colonos do sul do país sobre a matemática e a escola de seu tempo. Revista Brasileira de Educação. Rio de Janeiro. v.13, n.39, p.555-599, 2008.

LIMA, Adriana Cozim de Oliveira. As Civilizações em seus Sistemas de Numeração. 2008. Monografia (Especialização em Educação Matemática) - Universidade Estadual de Mato Grosso do Sul, 2008.2 Disponível em: <file://C:/Users/Jana\%C3\%ADna\%20mendes/Downloads/as\%20civilizacoes\%20em\%20seus\%20sist emas\%20de\%20numeracao.pdf>. Acesso em: 16 jun. 2015.

MACHADO, Alexandre N. As Investigações Filosóficas de Wittgenstein:Estilo e Método. COLÓQUIO PRAZER DO TEXTO, 2. São Lázaro, UFBA, 2006. Disponível em: $<$ http://www.academia.edu/292110/As_Investiga\%C3\%A7\%C3\%B5es_Filos\%C3\%B3ficas_De_Witt genstein_Estilo_E_M\%C3\%A9todo $>$. Acesso em: 13 mar. 2015

MARCONI, Marina de Andrade; LAKATOS, Eva Maria. Metodologia do Trabalho Científico: procedimentos básicos, pesquisa bibliográfica, projeto e relatório, publicações e trabalhos científicos. 7ª. Ed. - 3. reimpr. - São Paulo: Atlas, 2009.

NEVES, Cristiano. A linguagem viva Wittgenstein e os jogos de linguagem: a comunicação em uma organização prisional. Tese (Doutorado em Ciências da Linguagem) - Universidade do Sul de Santa Catarina, 2014.

PASSOS, Caroline Mendes. Conexões Teóricas e Práticas entre Etnomatemática e Educação Matemática Crítica. In: EBRAPEM, 12. 2008. Rio Claro. Anais... Rio Claro: IGCE, 2008. p. 01-17. Disponível em: <http://www2.rc.unesp.br/eventos/matematica/ebrapem2008/upload/236-1-Agt7_passos_tc.pdf>. Acesso em: 15 mar. 2015.

RUY, Mateus Cazelato. O conceito de jogos de linguagem nas Investigações Filosóficas de Wittgenstein. Universidade Estadual de Londrina, p. 01-13, 2008. Disponível em $<$ http://www.uel.br/eventos/sepech/sepech08/arqtxt/resumos-anais/MateusCRuy.pdf $>$. Acessado em 20 de mai. 2015

SANTOS, Benerval Pinheiro. Etnomatemática e suas possibilidades pedagógicas: algumas indicações. In: ENCONTRO PAULISTA DE EDUCAÇÃO MATEMÁTICA, 6. 2006. São Paulo. Anais... São Paulo. 2006. (s/p) Disponível em: < http://www.mat.uc.pt/ mat1287/texto/etnomatematica.htm > Acesso em: 30 mar. 2015.

VILELA, Denise S. Matemáticas nos usos e jogo de linguagem: ampliando concepções na Educação Matemática. 247p. Tese (Doutorado) - Faculdade de Educação, Unicamp. Campinas, SP, 2007. Disponível

em: $<$ http://www.educadores.diaadia.pr.gov.br/arquivos/File/2010/artigos teses/2011/matematica/maio/tes e denise silva vilela.pdf $>$. Acessado em: 18 de mai. 2015.

WANDERER, Fernanda. Educação Matemática e artefatos pedagógicos de escolas rurais multisseriada. Caderno pedagógico, Lajeado, v. 9, n. 1, p. 51-66, 2012.

WANDERER, Fernanda. Etnomatemática e o pensamento de Ludwig Wittgenstein. Acta Scientiae Revista de Ensino e Ciências e Matemática.: Canoas, ano 15, n. 2. p. 257-270, 2013.

WITTGENSTEIN, Ludwig. Investigações Filosóficas. Trad. José Carlos Bruni. São Paulo: Nova Cultural, 1999. 